\title{
Temperature-dependent accumulation mode particle and cloud nuclei concentrations from biogenic sources during WACS 2010
}

\author{
L. Ahlm ${ }^{1, *}$, K. M. Shakya ${ }^{1, * *}$, L. M. Russell ${ }^{1}$, J. C. Schroder ${ }^{2}$, J. P. S. Wong ${ }^{3}$, S. J. Sjostedt ${ }^{4, * * *}$, K. L. Hayden ${ }^{4}$, \\ J. Liggio $^{4}$, J. J. B. Wentzell ${ }^{4}$, H. A. Wiebe ${ }^{4}$, C. Mihele ${ }^{4}$, W. R. Leaitch ${ }^{4}$, and A. M. Macdonald ${ }^{4}$ \\ ${ }^{1}$ Scripps Institution of Oceanography, University of California, San Diego, La Jolla, California, USA \\ ${ }^{2}$ Department of Chemistry, University of British Columbia, Vancouver, BC, Canada \\ ${ }^{3}$ Department of Chemistry, University of Toronto, Toronto, Ontario, Canada \\ ${ }^{4}$ Science and Technology Branch, Environment Canada, Toronto, Ontario, Canada \\ * now at: Department of Applied Environmental Science, Stockholm University, Sweden \\ *** now at: Division of Environmental Health, Department of Public Health, School of Public Health and Health Sciences, \\ University of Massachusetts, Amherst, Massachusetts, USA \\ *** now at: Department of Chemistry and Biochemistry, Georgia Institute of Technology, Atlanta, Georgia, USA
}

Correspondence to: L. M. Russell (lmrussell@ucsd.edu)

Received: 12 October 2012 - Published in Atmos. Chem. Phys. Discuss.: 24 October 2012

Revised: 12 February 2013 - Accepted: 8 March 2013 - Published: 25 March 2013

\begin{abstract}
Submicron aerosol particles collected simultaneously at the mountain peak (2182 $\mathrm{m}$ a.s.l.) and at a forested mid-mountain site (1300 ma.s.l.) on Whistler Mountain, British Columbia, Canada, during June and July 2010 were analyzed by Fourier transform infrared (FTIR) spectroscopy for quantification of organic functional groups. Positive matrix factorization (PMF) was applied to the FTIR spectra. Three PMF factors associated with (1) combustion, (2) biogenics, and (3) vegetative detritus were identified at both sites. The biogenic factor was correlated with both temperature and several volatile organic compounds (VOCs). The combustion factor dominated the submicron particle mass during the beginning of the campaign, when the temperature was lower and advection was from the Vancouver area, but as the temperature started to rise in early July, the biogenic factor came to dominate as a result of increased emissions of biogenic VOCs, and thereby increased formation of secondary organic aerosol (SOA). On average, the biogenic factor represented $69 \%$ and $49 \%$ of the submicron organic particle mass at Whistler Peak and at the mid-mountain site, respectively. The lower fraction at the mid-mountain site was a result of more vegetative detritus there, and also higher influence from local combustion sources.

The biogenic factor was strongly correlated $(r \sim 0.9)$ to number concentration of particles with diameter $\left(D_{\mathrm{p}}\right)>$
\end{abstract}

$100 \mathrm{~nm}$, whereas the combustion factor was better correlated to number concentration of particles with $D_{\mathrm{p}}<100 \mathrm{~nm}$ $(r \sim 0.4)$. The number concentration of cloud condensation nuclei $(\mathrm{CCN})$ was correlated $(r \sim 0.7)$ to the biogenic factor for supersaturations $(S)$ of $0.2 \%$ or higher, which indicates that particle condensational growth from biogenic vapors was an important factor in controlling the $\mathrm{CCN}$ concentration for clouds where $S \geq 0.2 \%$. Both the number concentration of particles with $D_{\mathrm{p}}>100 \mathrm{~nm}$ and numbers of CCN for $S \geq 0.2 \%$ were correlated to temperature. Considering the biogenic influence, these results indicate that temperature was a primary factor controlling these $\mathrm{CCN}$ concentrations at $0.2 \%$ supersaturation.

\section{Introduction}

Atmospheric aerosols affect climate by scattering and absorbing incoming solar radiation and by acting as cloud condensation nuclei (CCN). The climatic impact of aerosol particles depends on their size and composition. Organic aerosols make up a significant fraction (20-90\%) of the submicrometer particulate mass (e.g., Jimenez et al., 2009). Whereas the formation process of inorganic aerosols such as sulfate, nitrate, and ammonium is fairly well understood, large 
uncertainties remain concerning the formation of secondary organic aerosol (SOA) from oxidation products of volatile organic compounds (VOCs) (e.g., Hallquist et al., 2009). Globally, emissions of biogenic VOCs (BVOCs) are estimated to be an order of magnitude larger than anthropogenic VOCs (Goldstein and Galbally, 2007), and oxidation of BVOCs yields a large biogenic contribution to SOA, estimated to be in the range of $12-70 \mathrm{Tg} \mathrm{yr}^{-1}$ (Hallquist et al., 2009). The SOA concentration has been predicted to increase by over $100 \%$ until the year 2100 (Tsigaridis and Kanakidou, 2007) due to future expansion of boreal and temperate forests, and thereby increasing BVOC emissions.

The forested regions surrounding Whistler, British Columbia, Canada, present a large source of biogenic aerosols and trace gases that have previously been the center for biogenic particle studies (Schwartz et al., 2010; Leaitch et al., 2011; Takahama et al., 2011). Schwartz et al. (2010) quantified organic aerosol functional groups at a mid-mountain site at Whistler Mountain in May and June 2008 using Fourier transform infrared (FTIR) spectroscopy. By applying positive matrix factorization (PMF) to FTIR spectra and investigating correlations between factors and tracers, they estimated that $65 \%$ of the organic mass was from biogenic sources, and the remaining fraction from combustion sources. Takahama et al. (2011) performed similar measurements at Whistler Mountain in 2009, and in addition to biogenic and combustion aerosols also observed biomass burning particles. Leaitch et al. (2011) found an exponential increase in the submicron organic aerosol mass concentration, with increasing temperature consistent with modeled emissions of BVOCs as a function of temperature.

The Whistler Aerosol and Cloud Study (WACS) 2010, a large measurement campaign with focus on aerosols and clouds at Whistler Mountain, was carried out in June and July 2010. Macdonald et al. (2013) give an overview of the campaign, and found that organic compounds largely dominated the aerosol throughout most of the campaign. In this study we focus on the organic aerosol during WACS 2010, and investigate the sources responsible for the organic aerosol mass during four periods with different meteorological conditions and advection from different areas. In addition, we investigate the sources or processes that control the particle number concentration. Finally, we explore links between the organic aerosol and CCN concentrations, and the sources and processes that controlled the $\mathrm{CCN}$ population during this campaign. Unlike previous campaigns at Whistler, we use aerosol and gas-phase data sampled simultaneously at two different sites at different altitudes on Whistler Mountain in order to investigate local sources, formation and transport of organic aerosols.

\section{Sites and methods}

\subsection{Field sites}

The measurements in this study were performed simultaneously at two sites on Whistler Mountain: Whistler Peak (WHI), at an altitude of $2182 \mathrm{~m}$ a.s.l.; and Raven's Nest (WRN), a mid-mountain site at $1300 \mathrm{~m}$ a.s.l. Raven's Nest is located near halfway between Whistler Village (650 m a.s.l.) and WHI.

WHI is approximately $400 \mathrm{~m}$ above the tree line. Raven's Nest is surrounded by forest composed mostly of coniferous trees such as fir, hemlock and cedar. These sites may also be influenced from biomass burning aerosols in the summer, but during WACS 2010 such an influence was present only during the last three days of the study. Vancouver is the closest large city to Whistler, located approximately $100 \mathrm{~km}$ to the south. The two sites employed in this study are described more extensively in Macdonald et al. (2013), Pierce et al. (2012), and Wong et al. (2011).

\subsection{Experimental}

\subsubsection{Filter sampling and analysis}

Submicron particles were collected on $37 \mathrm{~mm}$ teflon filters (Teflo, Pall Inc., Ann Arbor, MI) at both Raven's Nest and Whistler Peak. At Raven's Nest the filters were sampled from 21 June to 28 July. All filters at Raven's Nest were sampled for $24 \mathrm{~h}$, and were changed at 09:00 local time (LT) every morning. The sampling setup included two filters sampled simultaneously, one with a diffusion dryer located upstream of the holder. In this manner dried and nondried aerosol was sampled simultaneously.

At Whistler Peak, filters were sampled from 19 June to 28 July. The mean sampling times were three days for the period 19 June-2 July and $24 \mathrm{~h}$ from 2 July-28 July. The filters were changed at 09:00 LT. The sampler did not include a dryer at Whistler Peak. Filters were housed in a refrigerator at ca. $5^{\circ} \mathrm{C}$ during sampling to reduce volatilization of organic compounds.

At both sites a duplicate back filter was located behind each sampling filter to provide a measurement for adsorption during sampling and contamination during handling and storage. After sampling, the filters were kept frozen to prevent volatilization of the aerosol.

Fourier transform infrared (FTIR) spectroscopy was used to quantify organic functional groups of the aerosol samples, including alkane, alkene, hydroxyl, carboxylic acid, nonacidic carbonyl, primary amine, and organonitrate groups. Each filter was scanned both before and after sampling using a Bruker Tensor 27 FTIR Spectrometer with a deuterated tryglycine sulfate (DTGS) detector (Bruker, Waltham). The prescanned spectrum was subtracted from the postscanned spectrum in order to correct for absorption 
by the teflon filter itself. An algorithm described by Russell et al. (2009) was used to provide baselining, peak fitting, and error estimation. The dried and nondried filter samples from Raven's Nest had close to identical functional group concentrations resulting from the FTIR analysis. Therefore, throughout this paper only the nondried filters from Raven's Nest will be included in the discussion for a more direct comparison with those at Whistler Peak where no dryer was involved in the filter sampling.

Organosulfate groups were investigated by a method described by Russell et al. (2009), where filter samples are rinsed with hexane to separate organosulfate groups from bisulfate and carbonate since these compounds all have absorbance peaks at $876 \mathrm{~cm}^{-1}$. However, none of the filters had organosulfate concentrations above detection limit after rinsing.

Most of the filter samples, from both Whistler Peak and Raven's Nest, were also analyzed with X-ray fluorescence (XRF) which provides elemental composition of the aerosol, including all elements heavier than $\mathrm{Na}$ (Maria et al., 2003). The XRF analysis was conducted by Chester LabNet (Tigard, Oregon).

\subsubsection{Spectromicroscopy}

Particles were also collected on silicon nitride windows $\left(\mathrm{Si}_{3} \mathrm{~N}_{4}\right.$, Silson Ltd.), and were later analyzed by scanning transmission X-ray microscopy with near-edge X-ray absorption fine structure (STXM-NEXAFS) spectroscopy at the Advanced Light Source (ALS) at Lawrence Berkeley National Laboratories (Beamline 5.3.2). Particles were analyzed for carbon K-edge by scanning at energy levels between 278 and $320 \mathrm{eV}$ (Kilcoyne et al., 2003). Spectra from ALS were processed using algorithms developed by Takahama et al. (2010), and using aXis software (Hitchcock, 2000). These measurements and the described analysis provide information of single particle organic functional groups of carbon containing particles as well as their size and morphology (Takahama et al., 2007).

\subsubsection{Complementary measurements}

The nonrefractory chemical components of the submicron aerosol particles were measured using aerosol mass spectrometry at both Whistler Peak and Raven's Nest. An Aerodyne Compact Time-of-Flight aerosol mass spectrometer (CToF-AMS) (Drewnick et al., 2005) was used at Whistler Peak, and a High-Resolution Time-of-Flight aerosol mass spectrometer (HR-ToF-AMS) (DeCarlo et al., 2006) was used at Raven's Nest.

Particle number size distributions were measured with TSI Scanning Mobility Particle Sizers (SMPS). An SMPS (3081L column and 3775 CPC) was used at Whistler Peak for particles in the 14-600 nm diameter interval, and at Raven's Nest for particles in the 16-700 nm diameter interval.
Number concentrations in the $0.65-20 \mu \mathrm{m}$ diameter interval were measured with a TSI Aerodynamic Particle Sizer (APS) at Raven's Nest. At Whistler Peak, number concentrations in the $0.25-32 \mu \mathrm{m}$ diameter interval were measured with an optical particle counter (OPC).

Numbers concentrations of $\mathrm{CCN}$ at different supersaturations $(S)$, in the range $0.07-1.0 \%$, were measured with a CCN counter from Droplet Measurement Technologies, Inc. (DMT-200 CCN counter) (Roberts et al., 2003).

Black carbon (BC) number concentrations with a mass equivalent diameter interval of 90-270 $\mathrm{nm}$ were measured at each site with a Single Particle Soot Photometer (SP2), from Droplet Measurement Technologies, Inc.

Mixing ratios of several VOCs were measured using proton transfer reaction mass spectrometry (PTR-MS). A quadrupole PTR-MS was used at Whistler Peak, and a timeof-flight PTR-MS (PTR-ToF-MS) was used at Raven's Nest.

Measurements of $\mathrm{NO}$ and $\mathrm{NO}_{2}$ were conducted at both Whistler Peak and Raven's Nest using a chemiluminescencebased $\mathrm{NO} / \mathrm{NO}_{\mathrm{x}}$ instrument (Thermo Scientific Model 42C$\mathrm{TL}$ ) with a photolytic converter specific for $\mathrm{NO}_{2}$ detection. In addition, meteorological measurements of parameters including temperature, relative humidity, and wind speed were made at both sites.

\section{Results and discussion}

\subsection{Time series}

Most measurements in this study were performed during the time period of the WACS 2010 campaign, 20 June to 28 July 2010. During this period organics contributed on average $89 \%$ at Whistler Mountain and $74 \%$ at Raven's Nest to the submicron particle mass sampled by the AMS. The corresponding contribution from sulfate was only $7 \%$ and $19 \%$, respectively, at the two sites, and the contributions from ammonium and nitrate were below $5 \%$ at both sites.

The WACS 2010 campaign is divided into four different periods based on differences in meteorology, air mass back trajectories, and aerosol and gas-phase chemistry (Macdonald et al., 2013). Period 1, covering the start of the campaign to 5 July, was characterized by cloudy conditions, high relative humidity, low temperatures (Fig. 2a) and snow remaining at both Whistler Peak and Raven's Nest. Back trajectories were predominantly from the south or southwest during this period (Fig. 1a), indicating advection from the Vancouver area. The average FTIR organic aerosol concentrations during period 1 were $1.7 \mu \mathrm{g} \mathrm{m}^{-3}$ and $1.0 \mu \mathrm{g} \mathrm{m}^{-3}$ at Raven's Nest and Whistler Peak, respectively. The organic aerosol was dominated by alkane and carboxylic acid groups at both sites (Fig. 2b-c), which is typical for an aerosol associated with anthropogenic combustion (e.g., Schwartz et al., 2010; Takahama et al., 2011). Few filters at Whistler Peak belonging to period 1 were analyzed by XRF, but from the XRF 

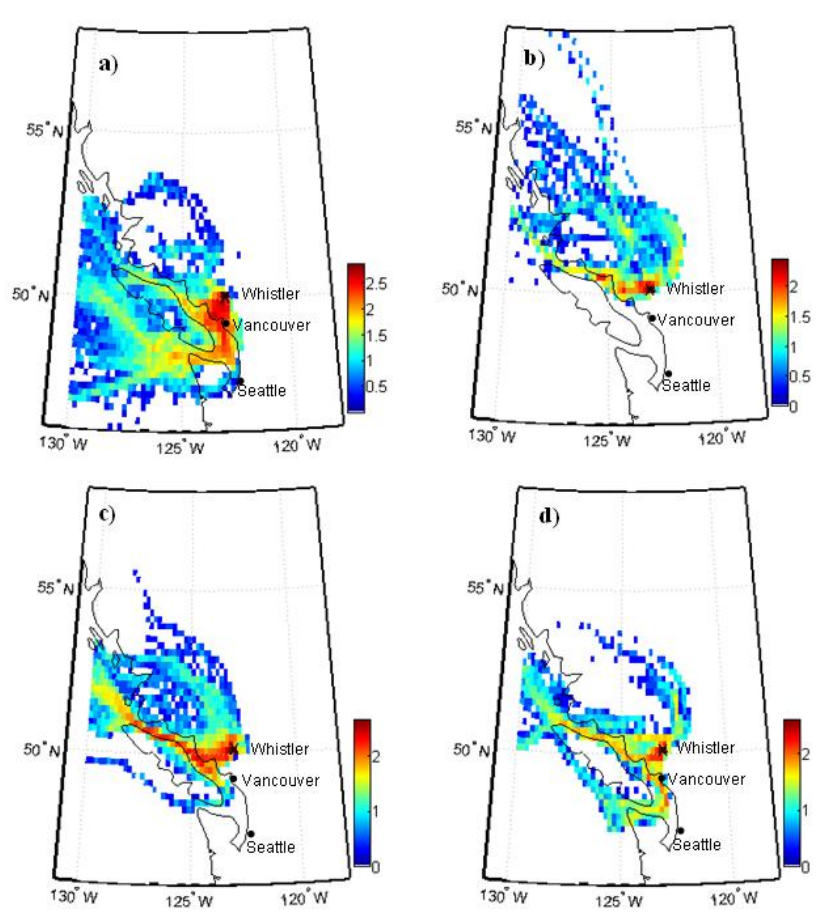

Fig. 1. HYSPLIT back trajectory (72 h) analysis for trajectories initiated at Whistler, with meteorological data sets from the Eta Data Assimilation System (EDAS) for (a) period 1, (b) period 2, (c) period 3, and (d) period 4 . The color scale indicates $\log _{10}$ of the number of trajectories that have passed through a certain grid cell. The grid cells are 0.2 degrees wide in both latitudinal and longitudinal direction. For every day, 24 back trajectories have been calculated with an interval of one hour between each trajectory.

concentrations in the filters sampled at Raven's Nest (Fig. 2g) the concentrations of the submicron dust elements $\mathrm{Al}, \mathrm{Si}, \mathrm{Ca}$, and $\mathrm{Fe}$ were relatively low during this period compared to the later periods. Also, concentrations of coarse-mode particle number concentrations were low during period 1 (Fig. 2h), indicating low dust concentrations for particles larger than $1 \mu \mathrm{m}$.

Period 2 (5-11 July) was initiated by rapidly increasing temperature (Fig. 2a), which was followed by increased concentrations of the biogenic tracers monoterpene, isoprene, methyl vinyl ketone/methacrolein (MVK/MACR) (Fig. 2de), accompanied by increasing concentrations of organic aerosols (Fig. 2b-c). (The PTR-MS cannot resolve MVK from MACR, so MVK/MACR denotes the sum of the two). Organic aerosol concentrations, as quantified by the FTIR analysis, reached almost $8 \mu \mathrm{g} \mathrm{m}^{-3}$ at Raven's Nest and $4 \mu \mathrm{g} \mathrm{m}^{-3}$ at Whistler Peak on 10-11 July. The average FTIR organic concentrations during period 2 were 3.7 and $2.4 \mu \mathrm{g} \mathrm{m}^{-3}$ at Raven's Nest and Whistler Peak, respectively. At Raven's Nest the alcohol groups were at very high levels (Fig. 2c), reaching $3.1 \mu \mathrm{g} \mathrm{m}^{-3}$ on 10 July. At Whistler Peak, the alcohol concentration reached a maximum of only
$1.1 \mu \mathrm{g} \mathrm{m}^{-3}$ during period 2. The alkane and carboxylic acid groups had rather similar concentrations at the two sites. Unlike period 1, period 2 had significant concentrations of nonacid carbonyl, reaching a maximum of $1.2 \mu \mathrm{g} \mathrm{m}^{-3}$ at Raven's Nest, and $0.7 \mu \mathrm{g} \mathrm{m}^{-3}$ at Whistler Peak. Advection was during this period initially from the northerly areas, changing to easterly later during the period (Fig. 1b). The areas to the north and east of Whistler have relatively few anthropogenic sources. The skies were mostly clear with occasionally a few scattered cumulus based several hundred meters above the Whistler Peak site. That observation together with relatively strong diurnal variations in meteorological parameters such as temperature and relative humidity at Whistler Peak indicates that the mixed layer grew well above the peak of the mountain in daytime. The snow rapidly melted at Raven's Nest during period 2, and the warm and dry conditions contributed to higher concentrations of XRF dust elements (Fig. 2g) and coarse-mode particles (Fig. 2h). Snow, however, remained at Whistler Peak, where concentrations of dust were considerably lower (Fig. 2f), consistent with the observation of dust generated near Raven's Nest from mountain bikes and occasional vehicles.

Period 3, covering 12-22 July, was significantly warmer than period 1, but cooler than period 2 (Fig. 2a). Concentrations of monoterpenes, isoprene, MVK/MACR, and organic aerosols were lower than during period 2 (Fig. 2b-e). However, as the temperature slowly increased throughout this period, the VOC and organic aerosol concentrations also slowly increased to reach a maximum on 21-22 July. During period 3 the organic aerosol was again dominated by alkane and carboxylic acid groups, similar to period 1 , and the nonacid carbonyl concentrations were lower than those observed during period 2 at the two sites. The alcohol group fraction at Raven's Nest was significantly lower than during period 2, with the exception of 21-22 July, when the alcohol concentration reached $1.5 \mu \mathrm{g} \mathrm{m}^{-3}$. At Raven's Nest, the elemental concentrations of dust tracers (Fig. $2 \mathrm{~g}$ ) were lower than during period 2. However, at Whistler Peak, where the ground was still snow covered, concentrations of dust (Fig. 2f) were rather similar to those observed during period 2. There were very clear diurnal variations in VOC concentrations during this period, particularly at Raven's Nest (Fig. 2e). These variations were partly a result of upslope flows from the warmer valley in daytime and downslope flows from the colder, higher altitudes at night (Macdonald et al., 2013). Apart from the very start of this period, when there was temporarily increased cloudiness, period 3 was dominated by clear skies or scattered cumulus with bases well above the Whistler Peak site. Back trajectories indicate a more pronounced westerly component in the advection compared to period 1 and 2. There might also have been some influence from Vancouver in the south.

Period 4 (23-28 July) was similar to period 2 in that temperature was high, relative humidity low (Fig. 2a), and there were mostly cloud-free conditions. Increasing concentrations 


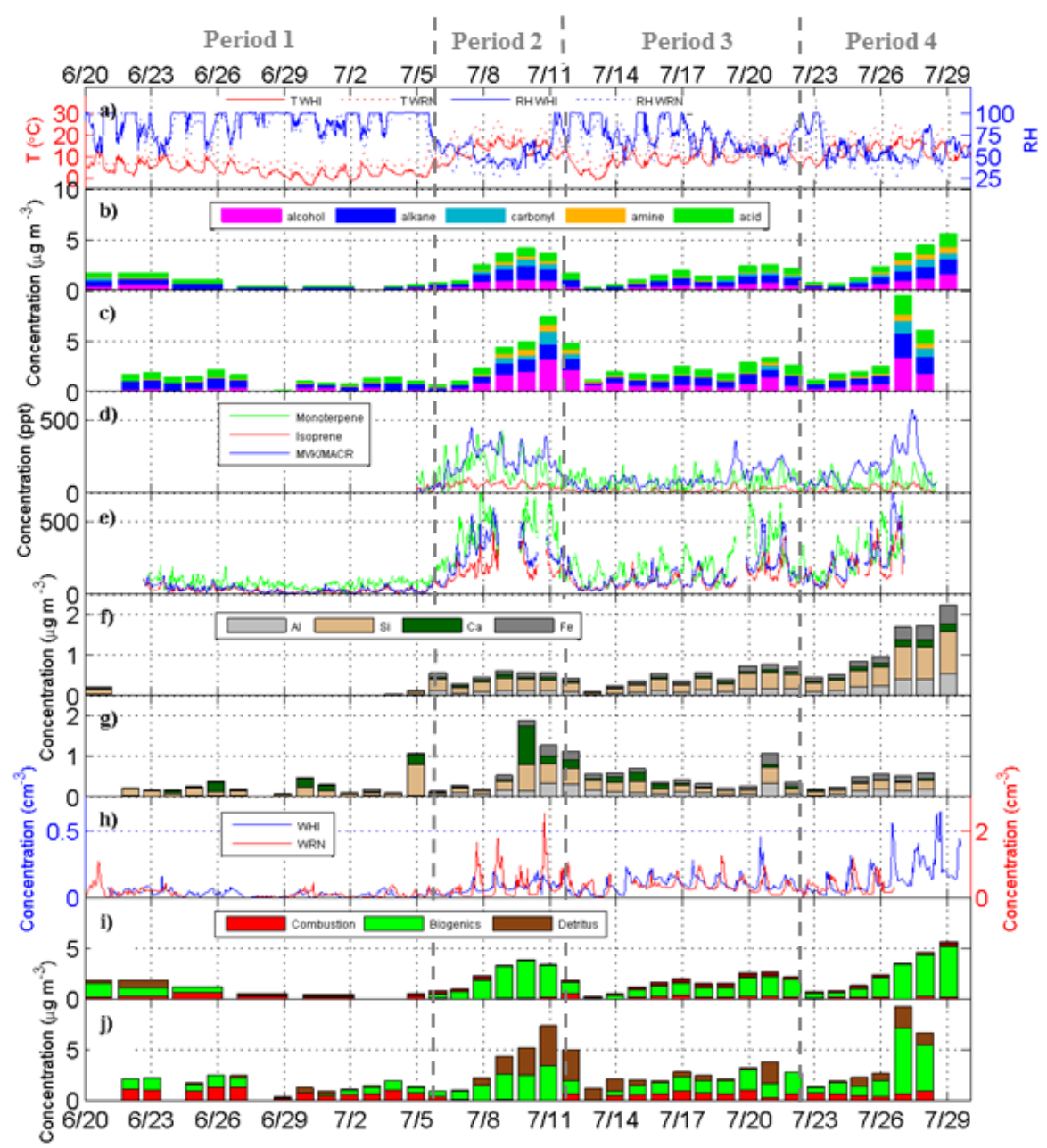

Fig. 2. Time series of temperature (T) and relative humidity (RH) (a), FTIR organic functional groups at WHI (b) and WRN (c), PTR-MS VOCs at WHI (d) and WRN (e), XRF dust elements at WHI (f) and WRN (g), coarse particle number concentrations (h), and PMF factors at WHI (i) and WRN (j).

of monoterpene, isoprene, MVK/MACR (Fig. 2d-e), and other VOCs were again accompanied by increasing concentrations of organic aerosols (Fig. 2b-e). During period 4, the organic aerosol again had significant contributions from alcohol and nonacid carbonyl groups, similar to period 2.

Unlike period 2, period 4 had some significant influence of biomass burning, among other things indicated by elevated acetonitrile and $\mathrm{BC}$ concentrations, from regional fires to the north (Macdonald et al., 2013). Dust concentrations increased significantly at the Whistler Peak site during period 4 (Fig. 2f), probably as a result of most of the snow having melted at the peak and generally higher winds at WHI.

\subsection{PMF analysis, sources of organic aerosols for each period at Raven's Nest and the peak}

Positive matrix factorization (PMF) (Paatero and Tapper, 1994) has been applied previously to FTIR spectra to iden- tify and explain the variability of measured components (e.g., Russell et al., 2009; Schwartz et al., 2010; Frossard et al., 2011; Liu et al., 2011; Takahama et al., 2011). In this study, PMF was applied to the baselined FTIR spectra from Whistler Peak and Raven's Nest. Solutions including 2-6 factors were investigated, and a range of fpeak values from -1 to 1 were used, varied in steps of 0.2 . Figure 3 shows how the ratio $Q / Q_{\text {expected }}$ (Ulbrich et al., 2009) depended on numbers of factors, and on fpeak value, at the two sites. This ratio has its minimum for an fpeak of zero for WHI, and close to zero for WRN. For solutions with five or six factors, two or more factors were not linearly independent. Furthermore, for solutions including more than four factors, one factor or more contributed less than $5 \%$ to the total organic mass. No source could be identified for these small contributions. Therefore, solutions with five factors or more were excluded, and a 4-factor solution was chosen for this study. Two of the four factors were weakly correlated 

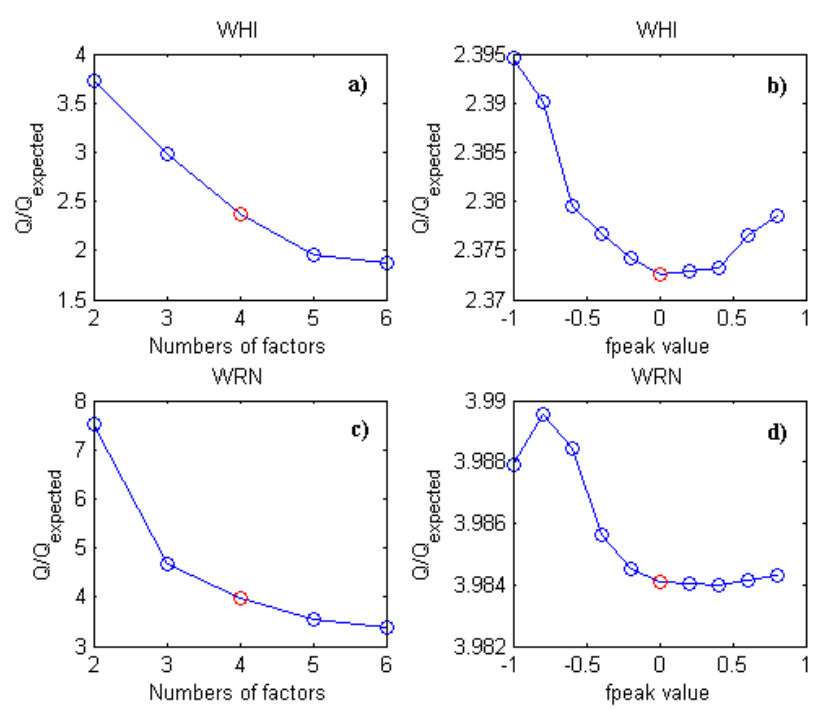

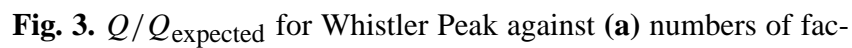
tors used, and (b) fpeak values for 4 factors. $Q / Q_{\text {expected for }}$ Raven's Nest against (c) numbers of factors used, and (d) fpeak values for 4 factors. The red circles show the chosen factor solution.

to each other at Whistler Peak $(r=0.31)$ and mildly correlated at Raven's Nest $(r=0.51)$ and also had very similar spectra, which differed only in the relative amount of alcohol (organic hydroxyl) group absorbance (between 3000 and $3500 \mathrm{~cm}^{-1}$ ). Because these factors are also correlated to similar tracer compounds, the separation was not sufficiently robust for either site, so we have combined them into a single factor.

Figure 4 shows the factor solutions chosen for Whistler Peak and Raven's Nest. Each factor at Raven's Nest has a parallel factor at Whistler Peak with a rather similar spectrum (Fig. 4a-c). Factor A (Fig. 4a) has the strong and characteristic ammonium absorbance with broad double peaks in the $2800-3400 \mathrm{~cm}^{-1}$ region that is observed for the anthropogenic combustion factors (Gilardoni et al., 2007; Hawkins et al., 2010; Takahama et al., 2011). A large fraction of factor A is comprised of alkane groups, $50 \%$ at Whistler Peak (Fig. 4d) and $49 \%$ at Raven's Nest (Fig. 4g); contributions from nonacid carbonyl and amine groups are low. Factor A was correlated to XRF sulfur with an $r$ coefficient of 0.77 at Whistler Peak (Table 1a), and 0.47 at Raven's Nest (Table 1b), which indicates that this factor is associated with fossil fuel combustion. Factor A was also correlated to $\mathrm{NO}_{\mathrm{x}}$ at Raven's Nest $(r=0.74)$ (Table 1b). At Whistler Peak the correlation to $\mathrm{NO}_{\mathrm{x}}$ is much weaker (Table 1a), suggesting that the combustion factor had a higher contribution from local combustion at Raven's Nest than at Whistler Peak, and a higher contribution from long-range transport at Whistler Peak than at Raven's Nest. Factor A is not correlated to any of the VOCs in Table 1, indicating low influence from biogenic VOCs (and acetonitrile) both at Whistler Peak and at
Raven's Nest. We will refer to factor A as a "combustion factor".

Factor B (Fig. 4b) is strongly dominated by alcohol groups, $65 \%$ at Whistler Peak (Fig. 4e), and $64 \%$ at Raven's Nest (Fig. 4h). This factor has the lowest contribution from alkane groups of all the factors. The contribution from amine groups to factor B is slightly higher at Raven's Nest (10\%) than at Whistler Peak $(4 \%)$, seen also in the absorbance at $3400 \mathrm{~cm}^{-1}$ in Fig. 4b, but apart from that the factor spectra are similar at the two sites. At Raven's Nest, factor B showed high correlation to XRF dust elements such as $\mathrm{Fe}, \mathrm{Al}, \mathrm{Mg}$, and $\mathrm{Mn}$ (Table 1b). Factor B was likely associated with vegetative detritus (e.g., Rogge et al., 1993; Hildemann et al., 1996), which may be coemitted with dust. The large fraction of alcohol groups in this factor is consistent with carbohydrate elements in plant materials (Bianchi et al., 1993). Liu et al. (2012) applied PMF to FTIR submicron organic aerosol spectra sampled in Bakersfield, CA, and found that one factor rich in alcohol (71\%) was correlated to the dust elements $\mathrm{Si}$, $\mathrm{Al}$, and $\mathrm{Ca}$. They associated that PMF factor with vegetative detritus that was resuspended with dust particles.

The hypothesis that factor B is associated with vegetative detritus is strengthened by the fact that factor B was correlated to phosphorus at both Raven's Nest (Table 1b) and Whistler Peak (Table 1a). Phosphorus is present in fluids circulating in plants and is an element associated with primary organic particles (Artaxo and Hansson, 1995; Artaxo et al., 1998). Factor B showed much lower correlation to the dust elements $\mathrm{Fe}, \mathrm{Al}, \mathrm{Mg}$, and $\mathrm{Mn}$ at Whistler Peak (Table 1a) than at Raven's Nest (Table 1b). This can be explained by the fact that there is little vegetation and generally little biogenic material on the ground around the Whistler Peak site, compared to the areas around Raven's Nest. Therefore, local emission of dust at Whistler Peak did not result in any coemission of vegetative detritus. Hence, most of the vegetative detritus associated with factor B was likely transported to the peak site from lower altitudes. Factor B will be referred to as a "detritus factor".

The combined factor $\mathrm{C}$ (Fig. 4c) differs from the other factors in that is has nonacid carbonyl, $17 \%$ at WHI (Fig. 4f) and $19 \%$ at WRN (Fig. 4i). These fractions are similar to the $16 \%$ nonacid carbonyl in the combined biogenic factor presented by Schwartz et al. (2010). Factor C was correlated with several of the PTR-MS gas-phase organic compounds like acetone, formic acid, methanol, acetic acid/glycoaldehyde, MVK/MACR, as well as temperature, at Whistler Peak (Table 1a) and at Raven's Nest (Table 1b). The correlations to biogenic VOCs (monoterpenes, isoprene) are weaker for WHI than for WRN, likely because the VOC emissions and the biogenic SOA formation is delayed by transport. However, WHI has the stronger correlation with intermediate products (MVK/MACR), suggesting that at least some of the photochemical formation may be happening locally. The correlation to temperature is logical because biogenic emissions of VOCs are temperature dependent (e.g., 

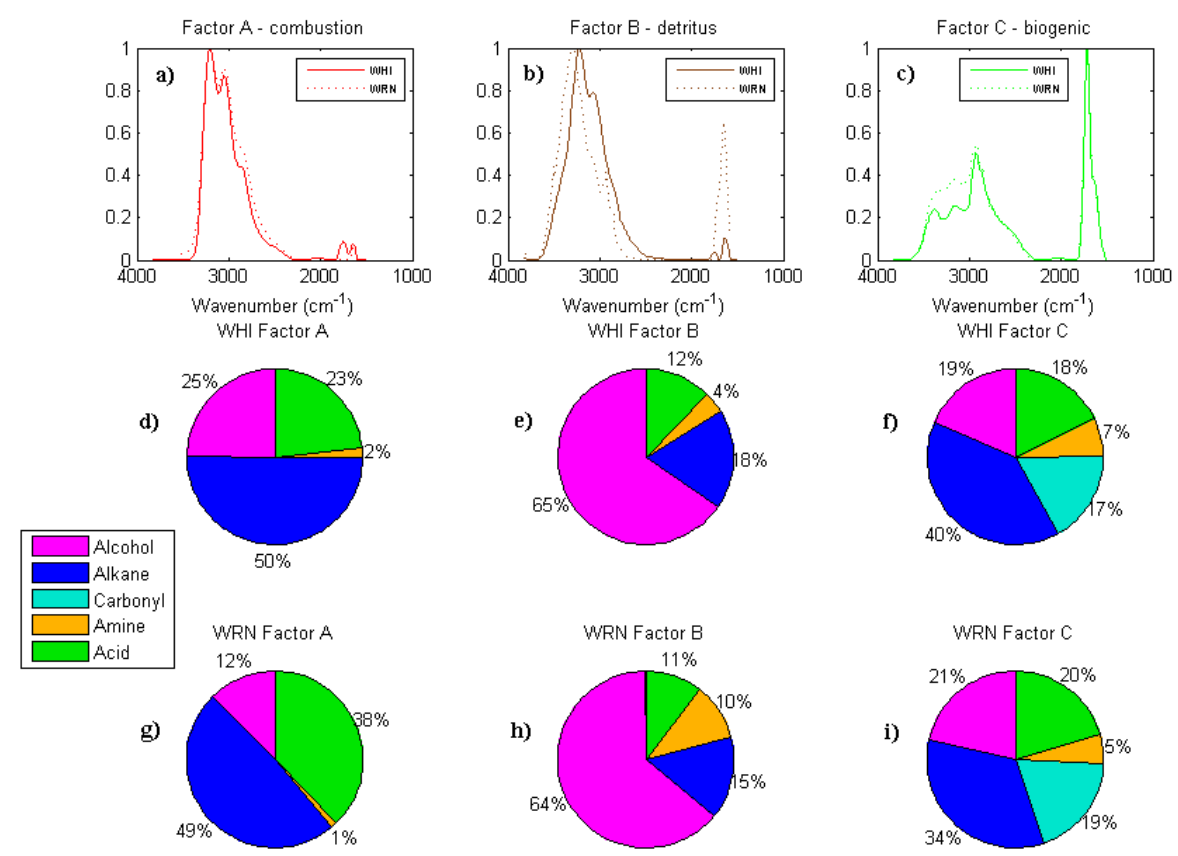

Fig. 4. PMF factor spectra for factors A-C for WHI (solid lines) and WRN (dotted lines) (a-c). Contributions from the different organic functional groups to factors $1-4$ at WHI (d-f) and WRN (g-i).

Table 1a. $r$ coefficients between the three PMF factors and tracers at Whistler Peak. All elements, gases, and parameters in the first column have been averaged over the same time intervals as the filters were sampled over $(\sim 24 \mathrm{~h})$, making up 31 points. The numbers within the brackets represent $90 \%$ confidence intervals calculated using the effective data size estimated from the first-order autocorrelation of each parameter (Mudelsee et al., 2010, algorithm 7.1).

\begin{tabular}{lrrr}
\hline WHI & Factor A & Factor B & Factor C \\
\hline $\mathrm{NO}_{\mathrm{x}}$ & $0.26(-0.08,0.55)$ & $-0.12(-0.44,0.23)$ & $0.43(0.18,0.63)$ \\
$\mathrm{S}$ & $0.77(0.59,0.88)$ & $0.22(-0.08,0.48)$ & $0.07(-0.34,0.46)$ \\
$\mathrm{Fe}$ & $0.06(-0.30,0.40)$ & $0.17(-0.19,0.45)$ & $0.85(0.60,0.95)$ \\
$\mathrm{Al}$ & $0.05(-0.31,0.40)$ & $0.17(-0.15,0.45)$ & $0.83(0.55,0.94)$ \\
$\mathrm{Mg}$ & $0.13(-0.23,0.46)$ & $0.18(-0.13,0.46)$ & $0.75(0.41,0.90)$ \\
$\mathrm{Mn}$ & $0.04(-0.32,0.39)$ & $0.12(-0.19,0.41)$ & $0.82(0.53,0.94)$ \\
$\mathrm{P}$ & $-0.08(-0.34,0.19)$ & $0.81(0.70,0.89)$ & $-0.09(-0.35,0.18)$ \\
Monoterpenes & $-0.46(-0.69,-0.16)$ & $-0.09(-0.37,0.21)$ & $0.39(0.13,0.60)$ \\
Isoprenes & $-0.57(-0.75,-0.30)$ & $-0.21(-0.48,0.08)$ & $0.42(0.16,0.62)$ \\
MVK/MACR & $-0.47(-0.68,-0.19)$ & $-0.19(-0.45,0.10)$ & $0.77(0.64,0.86)$ \\
Acetone & $-0.11(-0.42,0.22)$ & $-0.19(-0.46,0.11)$ & $0.98(0.96,0.99)$ \\
Methanol & $-0.24(-0.52,0.09)$ & $-0.13(-0.41,0.17)$ & $0.94(0.90,0.97)$ \\
Formic acid & $-0.24(-0.52,0.09)$ & $-0.20(-0.47,0.10)$ & $0.96(0.94,0.98)$ \\
Acetic acid/glycoaldehyde & $-0.11(-0.41,0.22)$ & $-0.35(-0.58,-0.07)$ & $0.89(0.82,0.94)$ \\
Acetonitrile & $-0.16(-0.44,0.14)$ & $-0.28(-0.52,0)$ & $0.42(0.18,0.62)$ \\
Temperature & $-0.34(-0.60,0)$ & $0.09(-0.24,0.41)$ & $0.73(0.57,0.84)$
\end{tabular}

Guenther et al., 1993). The combined factor $\mathrm{C}$ will be referred to as a "biogenic factor". However, it cannot be excluded that the biogenic factor had some potential influence from biomass burning during the last days of the campaign, when there were some high peaks in acetonitrile concentration and smoke associated with regional fires was visible (Macdonald et al., 2013).
The detritus factor was mildly correlated to factor $\mathrm{C}$ ( $r=$ $0.50)$ at Raven's Nest. However, there was no such corresponding correlation at Whistler Peak $(r=0.13)$. Therefore, we have chosen to not combine the detritus factor with the biogenic factor, but instead to keep it as an independent factor. This decision is also motivated by the fact that the organic 
Table 1b. $r$ coefficients between the three PMF factors and tracers at Raven's Nest. All elements, gases, and parameters in the first column have been averaged over the same time intervals as the filters were sampled over $\sim 24 \mathrm{~h}$, making up 36 points. The numbers within the brackets represent $90 \%$ confidence intervals (see Table 1a).

\begin{tabular}{lrrr}
\hline WRN & Factor A & Factor B & Factor C \\
\hline $\mathrm{NO}_{\mathrm{x}}$ & $0.74(0.55,0.86)$ & $-0.30(-0.58,0.04)$ & $0.04(-0.29,0.36)$ \\
$\mathrm{S}$ & $0.47(0.25,0.66)$ & $0.09(-0.19,0.36)$ & $0.12(-0.16,0.38)$ \\
$\mathrm{Fe}$ & $-0.42(-0.68,-0.06)$ & $0.87(0.71,0.94)$ & $0.49(0.12,0.74)$ \\
$\mathrm{Al}$ & $-0.43(-0.69,-0.08)$ & $0.87(0.71,0.94)$ & $0.47(0.09,0.73)$ \\
$\mathrm{Mg}$ & $-0.36(-0.63,-0.02)$ & $0.86(0.72,0.94)$ & $0.39(0.03,0.66)$ \\
$\mathrm{Mn}$ & $-0.38(-0.66,-0.01)$ & $0.90(0.77,0.96)$ & $0.48(0.11,0.74)$ \\
$\mathrm{P}$ & $-0.30(-0.58,0.05)$ & $0.78(0.56,0.89)$ & $0.28(-0.09,0.58)$ \\
Monoterpenes & $-0.54(-0.77,0.18)$ & $0.57(0.13,0.82)$ & $0.64(0.27,0.84)$ \\
Isoprenes & $-0.42(-0.71,0)$ & $0.54(0.04,0.82)$ & $0.83(0.58,0.93)$ \\
$\mathrm{MVK/MACR}$ & $-0.48(-0.74,-0.08)$ & $0.56(0.09,0.83)$ & $0.80(0.54,0.92)$ \\
Acetone & $-0.36(-0.67,0.09)$ & $0.63(0.19,0.86)$ & $0.82(0.58,0.93)$ \\
Methanol & $-0.44(-0.72,0.03)$ & $0.60(0.15,0.85)$ & $0.76(0.46,0.90)$ \\
Formic acid & $-0.44(-0.72,-0.04)$ & $0.66(0.24,0.87)$ & $0.83(0.60,0.93)$ \\
Acetic acid/glycoaldehyde & $-0.42(-0.71,0.02)$ & $0.70(0.32,0.89)$ & $0.84(0.64,0.94)$ \\
Acetonitrile & $-0.32(-0.62,0.05)$ & $0.38(-0.04,0.68)$ & $0.68(0.39,0.85)$ \\
Temperature & $-0.40(-0.71,0.03)$ & $0.49(-0.04,0.81)$ & $0.67(0.29,0.87)$ \\
\hline
\end{tabular}

functional group composition of the detritus factor strongly differ from the compositions of factor C (Fig. 4).

The contribution from each of the three final factors during the campaign can be seen in the time series in Fig. $2 \mathrm{i}-\mathrm{j}$ for Whistler Peak and Raven's Nest, respectively. The sum of the PMF factors for each sample closely matches the sum of the organic functional groups seen in Fig. $2 b-c$ for both sites. In general, the combustion factor concentration was higher at Raven's Nest than at the Whistler Peak site. This might again indicate that a significant fraction of the anthropogenic impact on the organic aerosol at Raven's Nest was from local sources, such as activities on the mountain or at Whistler Village in the valley.

Figure 5 shows the average contribution from each of the three PMF factors at the two sites during the whole campaign, and for the four subperiods discussed in Sect. 3.1. Over the range of the whole campaign, the biogenic factor dominated the submicron organic aerosol mass at both sites. During the cold and humid period 1, the combustion factor dominated at Raven's Nest. At Whistler Peak, on the other hand, the combustion factor made up the same fraction as the biogenic factor (Fig. 5). However, both the combustion factor and the biogenic factor were considerably lower at Whistler Peak than at Raven's Nest in concentration (Fig. 2i-j). The contribution from the detritus factor was low at Raven's Nest during period 1. The higher fraction of detritus at Whistler Peak is probably irrelevant since most of the detritus during period 1 comes from one single filter (Fig. 2i) sampled on 21-24 June (since the FTIR time resolution was low in the beginning of the campaign at the peak site).

During the warm and dry period 2, the contribution from the biogenic factor increased at both sites (Fig. 5), in partic- ular at the Whistler Peak site, where it strongly dominated $(83 \%)$. The detritus fraction at Raven's Nest was considerably higher during period 2 as a result of the very dry conditions during this period. The detritus factor made a much lower contribution at Whistler Peak than at Raven's Nest. Period 3 had higher influence from combustion than what was the case during period 2, but the biogenic factor still dominated at both sites. In period 4 the influence from combustion was lower than during period 3, and the dominance from the biogenic factor was large, likely then with some significant impact from biomass burning.

\subsection{Single particle analysis using STXM-NEXAFS}

In total, 47 particles were analyzed using STXM-NEXAFS. Two samples were from the Whistler Peak site and four from Raven's Nest (Table 2). All samples were collected in the daytime during the warm and dry period 2, when the influence from biogenic sources was high and the influence from combustion sources was at a minimum according to the PMF factor contributions in Fig. 5. Most of the sampled particles were in the size range of $1-5 \mu \mathrm{m}$ diameter.

The carboxylic acid group was the most dominant functional group in the analyzed samples, and was more pronounced at the Whistler Peak site compared to Raven's Nest (Fig. 6). There were several particles at both sites with the carboxylic peak being several times larger than the other peaks. An example of such a particle with its absorbance is shown in Fig. 7. The dominance of the carboxylic acid group might suggest a large fraction of SOA in the analyzed particles. Other functional groups such as alkyl, alcohol, and inorganic carbonate showed higher variability. Alkene, aromatic 


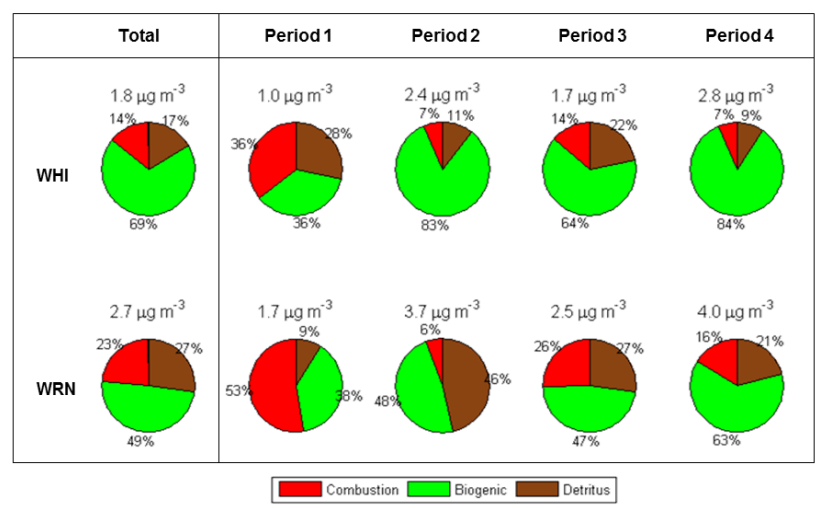

Fig. 5. Contributions from each PMF factor to the organic aerosol mass at WHI and WRN for the whole campaign, and for the four subperiods. The indicated concentration above each pie chart represents the average organic concentration for the specific period and site.

Table 2. Description of STXM samples.

\begin{tabular}{llll}
\hline Site & Date & Sampling time & No. of particles \\
\hline WHI & 9 July & $14: 10-15: 28$ & 4 \\
WHI & 10 July & $14: 52-16: 02$ & 10 \\
WRN & 5 July & $14: 00-15: 00$ & 3 \\
WRN & 8 July & $12: 42-13: 20$ & 17 \\
WRN & 9 July & $11: 59-12: 30$ & 10 \\
WRN & 10 July & $12: 23-12: 53$ & 3
\end{tabular}

and ketonic groups made a lower contribution compared to other functional groups.

At Whistler Peak during summer 2009, Takahama et al. (2011) observed large contributions from ketonic carbonyl, and alkene/aromatic groups indicating that the selected particles examined were tarballs observed in biomass burning episodes. However, during period 2 in this study, biogenic sources dominated and the acetonitrile concentrations stayed low, indicating low influence from biomass burning. Many of the single particles at both sites in Whistler had similar spectral features to SOA generated inside a smog chamber from $\alpha$-pinene (with or without isoprene), but none of the single particles collected at Whistler were similar to the SOA formed from 1,2,4-trimethylbenzene, an SOA precursor emitted from combustion sources (Shakya et al., 2013). These results corroborate with the large biogenic source for period 2 (Fig. 5) obtained from the PMF analysis and the contrast from previous study during 2009.

Based on cluster analyses (Takahama et al., 2007) of single particles analyzed by STXM-NEXAFS, Schwartz et al. (2010) found that a majority of their spectra were of particle types "secondary" and "other" at Whistler during summer 2008. The cluster analyses in this study also gave the result that most particles were of the type "SOA", and more so at

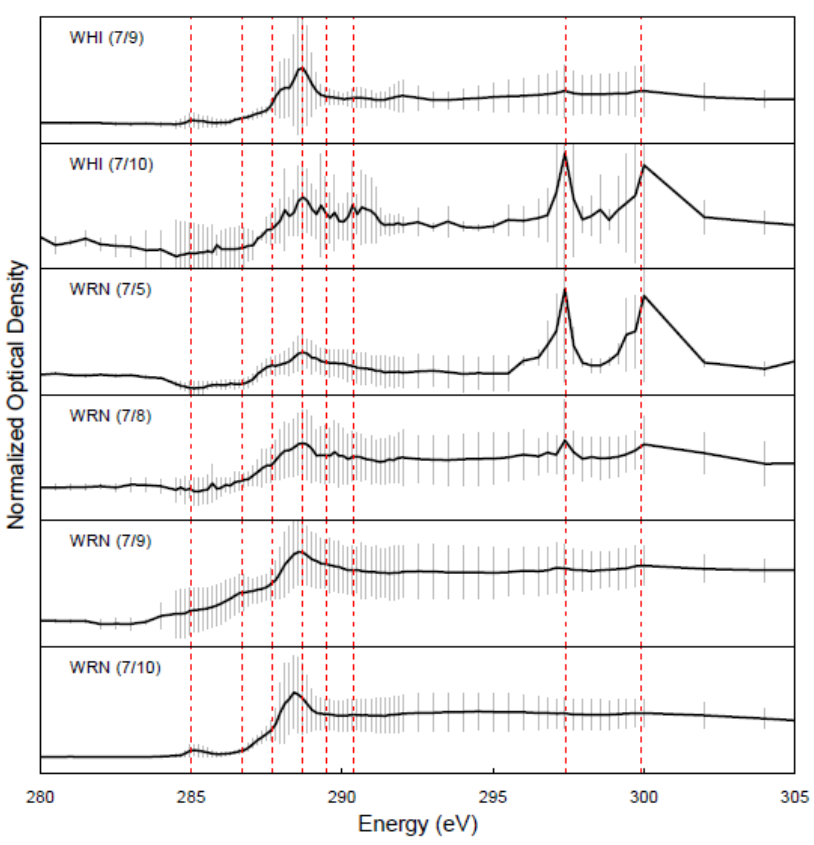

Fig. 6. The black solid lines represent the average of spectra of the particles from a specific sample. Gray vertical lines represent the standard deviation. Red dotted lines show the locations of the functional groups: $285 \mathrm{eV}$ for alkene, $286.7 \mathrm{eV}$ for ketonic carbonyl, $287.7 \mathrm{eV}$ for alkyl, $288.7 \mathrm{eV}$ for carboxylic carbonyl, $289.5 \mathrm{eV}$ for alcohol, $290.4 \mathrm{eV}$ for carbonate, and 297.4 and $299.9 \mathrm{eV}$ for $\mathrm{K}$ absorptions.
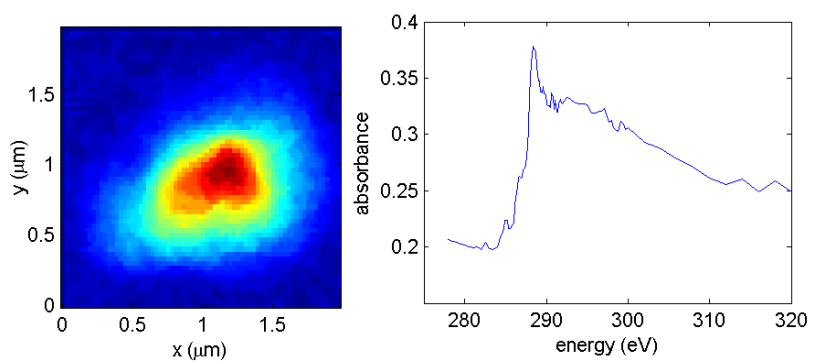

Fig. 7. An example of a particle with strong absorption in the $\mathrm{COOH}$ region $(288.7 \mathrm{eV})$. The left plot shows the representative absorbance image at $288.85 \mathrm{eV}$, and the right plot shows the average absorbance spectrum.

Whistler Peak $(\sim 2 / 3)$ compared to Raven's Nest $(\sim 1 / 2)$. Other particle types at Whistler Peak were soil dust, and at Raven's Nest biomass burning, combustion, and soil dust. These results are again consistent with the PMF results with a larger biogenic contribution at Whistler Peak $(83 \%)$ than at Raven's Nest (48\%) during period 2 (Fig. 5). 


\subsection{Links between particle number concentration, $\mathrm{CCN}$ and the PMF factors}

In Sects. 3.1-3.2, the focus was on the organic mass and sources responsible for the organic mass. In this section the focus will also be on the origins of the particle and $\mathrm{CCN}$ number concentrations as well as their associations. In particular, during period 3 (13-22 July), there were strong diurnal variations in VOC concentrations (Fig. 2d-e) and aerosol concentrations (Fig. 2h). Figure 8 shows median diurnal cycles of concentrations of total particle number, $\mathrm{SO}_{2}, \mathrm{NO}_{\mathrm{x}}$, and $\mathrm{BC}$ during period 3 at the two sites. In addition, median diurnal cycles of the ratios of the nonoxygenated AMS ion fragment $\mathrm{C}_{4} \mathrm{H}_{9}^{+}$and the oxygenated ion fragment $\mathrm{CO}_{2}^{+}$ to total organic aerosol concentration at Raven's Nest can be seen in Fig. 8. The AMS mass spectral peak $m / z 57$ contains the ion peaks $\mathrm{C}_{4} \mathrm{H}_{9}^{+}$and $\mathrm{C}_{3} \mathrm{H}_{5} \mathrm{O}^{+}$, and $m / z 44$ contains the ion peaks $\mathrm{CO}_{2}^{+}$and $\mathrm{C}_{2} \mathrm{H}_{4} \mathrm{O}^{+}$. Since the ion fragments of a certain $m / z$ measured by the C-ToF-AMS used at Whistler Peak cannot be separated, we have instead included the median diurnal cycles of the ratios of $\mathrm{m} / z 57$ and $\mathrm{m} / z$, 44 to total organic aerosol concentration for the Whistler Peak site in Fig. 8. All times mentioned here represent local time with daylight saving included. Sunrise occurred around 05:00 in the morning.

At Raven's Nest there was a very pronounced peak in $\mathrm{NO}_{\mathrm{x}}$ around 10:00 (Fig. 8c). This was likely a combined result of emissions from overnight and morning traffic in Whistler and the growing mixed layer reaching the altitude of Raven's Nest. At the same time, the particle number (Fig. 8a) and BC (Fig. 8d) concentrations also exhibited small peaks. For the $\mathrm{C}_{4} \mathrm{H}_{9}^{+}$-ratio (Fig. 8e), there is a slight and broad increase during the daytime visible at least in the third quartile, with broad similarity to the $\mathrm{BC}$ pattern. The $\mathrm{CO}_{2}^{+}$-ratio (Fig. 8f) stayed more constant during the day. Due to the morning correlation of particle number with $\mathrm{NO}_{\mathrm{x}}$ and $\mathrm{BC}$ at Raven's Nest, the slight peak in particle number concentration around 10:00 was likely due to primary aerosol particles emitted from local sources. Corresponding morning peaks were less evident at the Whistler Peak site (Fig. 8g, i, j, and k), likely because the mixed layer in general reached the level of the mountain peak in the afternoon when the layer had been more diluted during growth.

In the evening, between 18:00 and 20:00, the particle number concentration at Raven's Nest (Fig. 8a) had a second more pronounced peak. That was about the same time as the particle number concentration peaked at Whistler Peak (Fig. 8g). The BC concentration at Raven's Nest (Fig. 8d) also experienced a second maximum in the evening, similar to the particle number concentration. On this evening the BC peak was very pronounced at the Whistler Peak site as well (Fig. 8j). The fact that particle number and $\mathrm{BC}$ peaked at the same time in the evening at the two sites suggests that this peak was at least partly a result of anthropogenic sources. Also, $\mathrm{SO}_{2}$ experienced a maximum in the evening (Fig. $8 \mathrm{~b}$
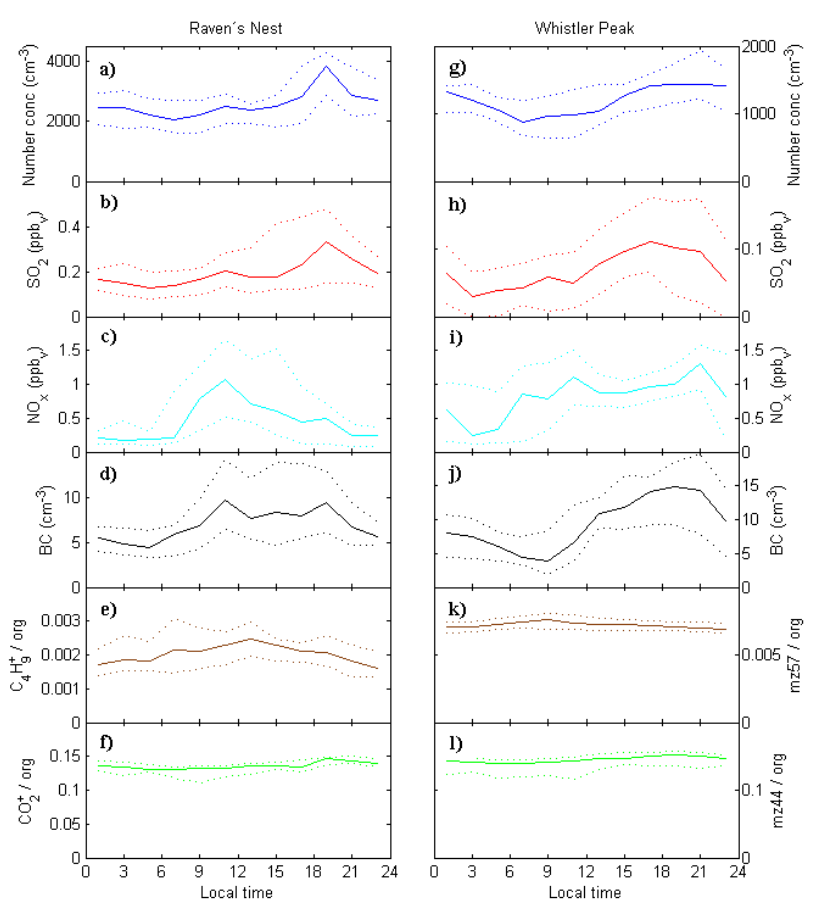

Fig. 8. Median diurnal cycles 13-22 July of total integrated SMPS particle number concentration, $\mathrm{SO}_{2}, \mathrm{NO}_{\mathrm{x}}$, and $\mathrm{BC}$ at Raven's Nest (a-d), and Whistler Peak $(\mathbf{g}-\mathbf{j})$. The ratios of $\mathrm{C}_{4} \mathrm{H}_{9}^{+}$and $\mathrm{CO}_{2}^{+}$to total organic concentration at Raven's Nest (e-f), and the ratios of $m / z 57$ and $m / z 44$ to total organic concentration at Whistler Peak (k-l). Dotted lines represent 25 and 75 percentiles, respectively.

and h). The back trajectories in Fig. 1c suggest that the daytime increase in $\mathrm{SO}_{2}$ may partly be a result of westerly air transport from a sulfur smelter source that is located at the coast.

The average total particle number concentrations over the whole campaign were 2290 and $1210 \mathrm{~cm}^{-3}$ at Raven's Nest and Whistler Peak, respectively. Table 3 shows median particle number concentrations for each of the four periods separately at the two sites. During period 1 the median number concentration at Raven's Nest was almost a factor of three higher than the corresponding concentration at Whistler Peak. This relative difference between the two sites was larger during period 1 than during the other three periods, likely as a result of occasional decoupling between the sometimes existing cloud layer at Whistler Peak with the boundary layer during period 1 .

Figure 9 includes time series of the integrated SMPS particle number size distribution (Fig. 9a), concentrations of total particle number and $\mathrm{NO}_{\mathrm{x}}$ (Fig. 9b), particle number concentrations in the particle diameter intervals 16$100 \mathrm{~nm}\left(N_{16-100}\right)$ and $100-700 \mathrm{~nm}\left(N_{100}\right)$ (Fig. 9c), and the PMF organic combustion and biogenic factors (Fig. 9d), at Raven's Nest. The particle number concentration followed the $\mathrm{NO}_{\mathrm{x}}$ concentration somewhat during period 1 (Fig. 9b), 
Table 3. Median concentrations of the integrated total particle number from the SMPS and BC from the SP2 during each period for the two sites.

\begin{tabular}{llrrrr}
\hline & Site & Period 1 & Period 2 & Period 3 & Period 4 \\
\hline Total number concentration $\left(\mathrm{cm}^{-3}\right)$ & WHI & 690 & 1500 & 1210 & 1570 \\
& WRN & 1980 & 2180 & 2540 & 2620 \\
SP2 number concentration $\left(\mathrm{cm}^{-3}\right)$ & WHI & 5.75 & 7.85 & 8.68 & 25.3 \\
& WRN & 7.05 & 3.57 & 6.39 & 7.78 \\
\hline
\end{tabular}

Table 4. Correlation coefficients between the integrated total particle number concentration from the SMPS with $\mathrm{BC}$, NO $\mathrm{x}_{\mathrm{x}}$, and $\mathrm{CO}$ during each period for the two sites. The correlations are calculated for $24 \mathrm{~h}$ averages of each parameter.

\begin{tabular}{llrrrr}
\hline & Site & Period 1 & Period 2 & Period 3 & Period 4 \\
\hline Correlation with BC & WHI & 0.10 & -0.57 & 0.71 & 0.89 \\
& WRN & 0.62 & 0.54 & 0.57 & 0.86 \\
Correlation with $\mathrm{NO}_{\mathrm{x}}$ & WHI & 0.21 & -0.51 & 0.34 & 0.43 \\
& WRN & 0.49 & 0.26 & 0.09 & 0.59 \\
Correlation with CO & WHI & -0.09 & -0.13 & -0.03 & 0.43 \\
& WRN & 0.49 & -0.03 & 0.10 & 0.50 \\
Correlation with $\mathrm{SO}_{2}$ & WHI & 0.45 & -0.16 & 0.08 & 0.21 \\
& WRN & -0.02 & 0.61 & 0.27 & 0.20 \\
\hline
\end{tabular}

particularly between 28 June and 5 July. However, the peaks in number concentration during the evenings on 24 June and 26 June (Fig. 9b) and growth from small sizes (Fig. 9a) could be results of nucleation events since $\mathrm{NO}_{\mathrm{x}}$ (Fig. $9 \mathrm{~b}$ ) and $N_{100}$ (Fig. 9c) remained low during these two growth events. There is no correlation between particle number and $\mathrm{SO}_{2}$ during period 1 at Raven's Nest (Table 4). However, $r$ coefficients between total particle number and $\mathrm{NO}_{\mathrm{x}}, \mathrm{BC}$, and $\mathrm{CO}$ are in the range $0.49-0.62$ for Raven's Nest (Table 4) suggesting a significant contribution to the particle numbers from anthropogenic sources during period 1. At Whistler Peak there are no such corresponding correlations, which again suggest that the Whistler Peak site was at times decoupled from the boundary layer during period 1 .

Period 2 started with two very clear nucleation events on 5 July and 6 July (Fig. 9a), which have been described in detail by Pierce et al. (2012). Period 2 had the lowest $\mathrm{NO}_{\mathrm{x}}$ concentration (Fig. 9b) and the lowest PMF combustion factor concentration (Fig. 9d) of all the periods. The $r$ coefficients between number concentration and $\mathrm{NO}_{\mathrm{x}}, \mathrm{BC}$, and $\mathrm{CO}$, are in general low or negative at both Raven's Nest and Whistler Peak during period 2 (Table 4), indicating low contribution from primary emissions. Hence, it appears that new particle formation largely dominated the particle number concentration during period 2. Total particle number concentrations are moderately correlated to $\mathrm{SO}_{2}(r=0.62)$ at Raven's Nest during period 2, but there is no such correlation at Whistler Peak, which could indicate that nucleation preferably occurred at lower altitudes.

$\mathrm{BC}$ number concentrations were higher during period 3 than during period 2 (Table 3). Furthermore, the $r$ coeffi- cients between particle number and $\mathrm{BC}$ are also higher during period 3 than during period 2 (Table 4). High peaks in both number concentration and $\mathrm{NO}_{\mathrm{x}}$ can be seen around midnight between 11 and 12 July (Fig. 9b), suggesting a plume of primary particles at that time. The $r$ coefficient between particle number and $\mathrm{SO}_{2}$ is lower during period 3 than during period 2 at Raven's Nest, suggesting that new particle formation from gas-phase oxidation of $\mathrm{SO}_{2}$ contributed less during period 3 than during period 2 .

Period 4 started with a very clear nucleation event in the afternoon of 22 July (Fig. 9a). There was a rapid increase in particle number and a simultaneous drop in $\mathrm{NO}_{\mathrm{x}}$ concentration during this event (Fig. 9b), and at the same time the number of accumulation mode particles remained low. Despite this nucleation event, period 4 has the highest correlations between particle number and $\mathrm{BC}, \mathrm{CO}$, and $\mathrm{NO}_{\mathrm{x}}$, all in the range $0.43-0.89$ (Table 4), indicating significant contributions from anthropogenic sources and/or biomass burning to the aerosol particle population; the higher BC concentrations during period 4 (Table 3) suggest a biomass burning contribution. This hypothesis is supported by observed large peaks in acetonitrile during the same time period.

Comparing Fig. $9 \mathrm{c}$ and d, it can be seen that $N_{16-100}$ follows the mass concentrations of the PMF combustion factor relatively well. $N_{16-100}$ is correlated with the combustion factor $(r=0.40)$ at Raven's Nest, but with neither the biogenic factor $(r=-0.20)$ nor the detritus factor $(r=-0.29)$. Hence, many of the particles smaller than $100 \mathrm{~nm}$ at Raven's Nest were likely related to combustion sources. This does not imply that the combustion factor mass was dominated 


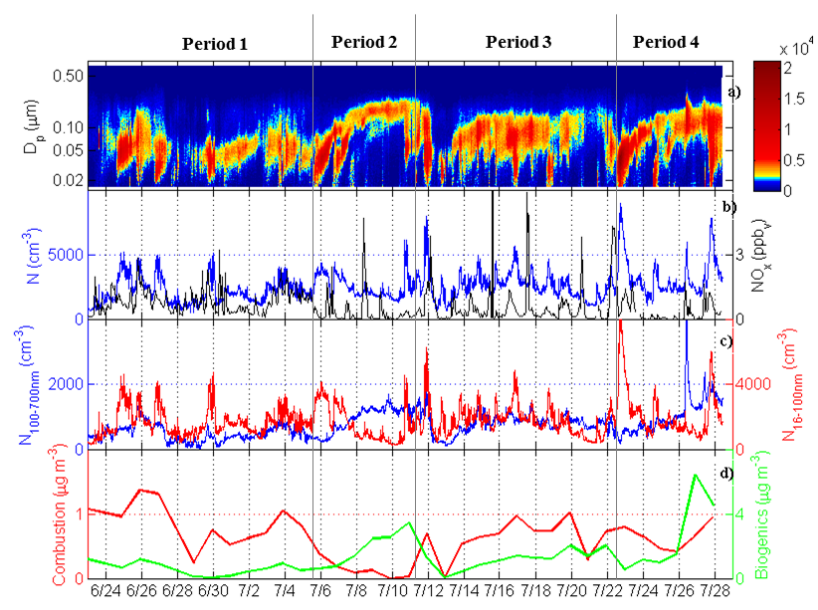

Fig. 9. Time series at Raven's Nest of (a) SMPS particle number size distribution (the color indicates $\mathrm{dN} / \mathrm{dlog}_{10} D_{\mathrm{p}}\left[\mathrm{cm}^{-3}\right]$ ), (b) SMPS total integrated particle number concentration (blue) and $\mathrm{NO}_{\mathrm{x}}$ concentration (black), and (c) $N_{100}$ (blue) and $N_{16-100}$ (red), and (d) the PMF combustion factor (red) and biogenic factor (green).

by ultrafine particles since fossil fuel combustion also emits particles that are larger than $100 \mathrm{~nm}$ (e.g., Kittelson, 1998).

Whereas $N_{16-100}$ follows the combustion factor in Fig. $9 \mathrm{c}-\mathrm{d}$ relatively well as discussed above, $N_{100}$ follows the concentration of the PMF biogenic factor. The associated $r$ coefficient for correlation between $N_{100}$ and the biogenic factor is 0.88 and 0.83 at Raven's Nest and Whistler Peak, respectively. There are no such clear correlations between $N_{100}$ and the combustion factor $(r=-0.01$ and $r=-0.15)$ or the detritus factor $(r=0.56$ and $r=-0.05)$ at the two sites, respectively. Since the biogenic factor was largely dominated by biogenic SOA throughout most of the campaign, except possibly during the last days of period 4 (Sect. 3.2), the high correlation between the biogenic factor and $N_{100}$ suggests that the concentration of particles larger than $100 \mathrm{~nm}$ was controlled to a large extent by particle condensational growth from biogenic vapors. Hence, although combustion sources contributed to $N_{16-100}, N_{100}$ depended critically on biogenic SOA in this study.

Many studies (e.g., Kapustin et al., 2006; Clarke and Kapustin, 2010) suggest the number concentration of particles with $D_{\mathrm{p}}>100 \mathrm{~nm}$ as a surrogate for the CCN concentration. Here we consider the scope of that assumption for a biogenic event. The correlation between the CCN concentration and the biogenic factor in general increased with increasing supersaturation (Table 5). For $S=0.2$ the $r$ coefficient was 0.69 , and for higher supersaturations the correlation was even stronger. Thus, the CCN number concentration was strongly related to the biogenic factor.

Temperature may influence the concentration of particles larger than $100 \mathrm{~nm}$ by increasing the emission of BVOCs. Figure $10 \mathrm{a}$ and $\mathrm{b}$ show the concentrations of particles larger
Table 5. Correlation coefficients between $24 \mathrm{~h}$ averages of the biogenic PMF factor and CCN number concentration at Raven's Nest for different supersaturations $(S)$. The numbers within the brackets represent $90 \%$ confidence intervals.

\begin{tabular}{cc}
\hline & $r$ coefficient \\
\hline$S=0.1$ & $0.35(0.04,0.60)$ \\
$S=0.2$ & $0.69(0.42,0.85)$ \\
$S=0.3$ & $0.78(0.57,0.89)$ \\
$S=0.5$ & $0.76(0.56,0.88)$ \\
\hline
\end{tabular}

than $100 \mathrm{~nm}$ as functions of local temperature at the two sites for the entire study. $N_{100}$ is strongly correlated to ambient temperature at both sites, which indicates that temperature was an important factor for $N_{100}$ at both sites. Figure 10c and $\mathrm{d}$ show the corresponding relations for numbers of $\mathrm{CCN}$ for $S=0.2 \%$ (Fig. 10c) and for $S=0.3 \%$ (Fig. 10d) at Raven's Nest. The correlation coefficient was similar for $S=0.5 \%(r=0.63)$. For $S=0.1 \%$ there was no correlation $(r=0.06)$ between the number of CCN and temperature. The relations and correlations in Fig. 10 are calculated from $24 \mathrm{~h}$ averages of temperature and $\mathrm{CCN}$ and particle concentrations, in order to minimize the impact of anabatic and katabatic flows on the correlations. If the correlations instead would have been calculated over a shorter time interval, e.g., one hour, part of the correlation could be a result of anabatic flows bringing warm air with high $\mathrm{CCN}$ concentration from the valley in daytime up to the mountain sites, and the opposite occurring at nighttime.

The particles here are predominantly composed of organics with some sulfate. The correlation between concentrations of particles larger than $100 \mathrm{~nm}$ and $\mathrm{CCN}$ at $S=0.2 \%$ at Raven's Nest (Fig. 10e) is strong; however, the CCN concentration at $S=0.2 \%$ is a factor of two lower than $\mathrm{N}_{100}$. Thus, in general we expect $N_{100}$ to provide some measure of CCN at $S=0.2 \%$ with variations of about a factor of two. We note that while the correlation of $N_{100}$ and $\mathrm{CCN}$ at $S=0.2 \%$ is strong (Fig. 10e), that of CCN at $S=0.2 \%$ with temperature (Fig. 10c) is weaker than the $N_{100}$ versus temperature (Fig. 10a). The weaker relationship of $\mathrm{CCN}$ at $S=0.2 \%$ with temperature may be a result of different hygroscopic properties for different aerosol particles. The hygroscopicity of sulfate is higher than that of organics. Furthermore, different types of organic particles like primary detritus particles and biogenic SOA are likely to have different hygroscopic properties, and also different dependences on temperature, which may explain the weaker relation for $\mathrm{CCN}$ with temperature than for $N_{100}$ with temperature. 

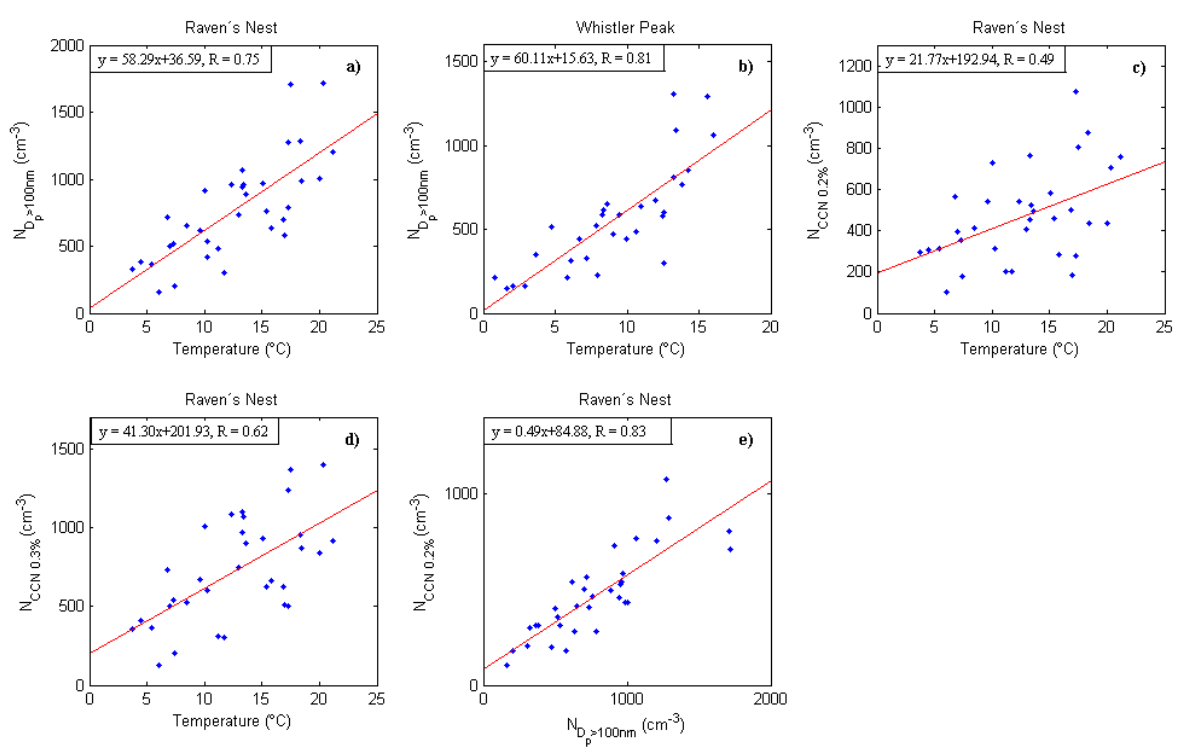

Fig. 10. Temperature dependency for numbers of particles with $D_{\mathrm{p}}>100 \mathrm{~nm}$ at Raven's Nest (a) and Whistler Peak (b) for numbers of CCN at Raven's Nest at a supersaturation of $0.2 \%$ (c) and $0.3 \%(\mathbf{d})$, and the relation between concentrations of CCN at a supersaturation of $0.2 \%$ and particles with $D_{\mathrm{p}}>100 \mathrm{~nm}$ at Raven's Nest (e). Each point represents a $24 \mathrm{~h}$ average. The red curves represent linear fits according to the given equation in each plot.

\section{Summary and conclusions}

PMF has been applied to FTIR spectra in order to investigate and quantify sources of submicron organic aerosols at Whistler Peak (2182 m a.s.l.) and Raven's Nest (1300 m a.s.l.) during the WACS 2010 campaign at Whistler Mountain, British Columbia. Here the key results and main conclusions are presented:

- The factors that could be identified at the two sites are (1) a combustion factor, (2) a biogenic factor, and (3) a vegetative detritus factor.

- The combustion factor dominated the organic aerosol mass at both sites during the early part of the campaign, which was characterized by low temperatures and advection from the Vancouver area. However, as the temperature started to rise in early July, the biogenic factor increased as a result of increased emissions of BVOCs, and came to be the largest factor throughout the rest of the campaign.

- The largest difference between the two sites in terms of organic aerosol composition was the much higher concentration of alcohol functional groups at Raven's Nest than at Whistler Peak during the dry mid-part of the campaign. These alcohol groups were likely associated with local emissions of vegetative detritus. The lower fraction of detritus at Whistler Peak was a result of a snow-covered surface at the peak of the mountain, and also little vegetation up there.
- On average over the whole campaign, the biogenic factor represented $69 \%$ and $49 \%$, the combustion factor represented $14 \%$ and $23 \%$, and the detritus factor represented $17 \%$ and $27 \%$ at Whistler Peak and Raven's Nest, respectively. The larger fraction of combustion at Raven's Nest compared to Whistler Peak was likely a result of some local pollution from Whistler Village in the valley.

The biogenic factor was correlated to temperature and to several VOCs. The number concentration of particles with $D_{\mathrm{p}}>100 \mathrm{~nm}$ was strongly correlated to the biogenic factor (and to temperature), whereas the number concentration of particles smaller than $100 \mathrm{~nm}$ was better correlated to the combustion factor. CCN measurements from Raven's Nest showed that the CCN concentration was correlated to temperature and to the biogenic factor for supersaturations equal to or larger than $0.2 \%$. This is an indication that temperature and biogenic SOA formation exerted a large control on the $\mathrm{CCN}$ population for supersaturations equal to or larger than $0.2 \%$ during this study.

Acknowledgements. Environment Canada funded the Whistler Aerosol and Cloud Study 2010 through the Clean Air Regulatory Agenda (CARA). Funding was provided through Environment Canada's Grants and Contribution program. Cooperation and support from Whistler-Blackcomb and Juniper Buller is gratefully acknowledged. We would also like to thank D. J. Cziczo for providing $\mathrm{CCN}$ data.

Edited by: V.-M. Kerminen 


\section{References}

Artaxo, P. and Hansson H. -C.: Size distribution of biogenic aerosol particles from the Amazon Basin, Atmos. Environ., 29, 393-402, 1995.

Artaxo, P., Fernandes, E. T., Martins, J. V., Yamasoe, M. A., Hobbs, P. V., Maenhaut, W., Longo, K. M., and Castanho, A.: Largescale aerosol source apportionment in Amazonia, J. Geophys., Res., 103, 31837-31847, 1998.

Bianchi, G., Gamba, A., Limiroli, R., Pozzi, N., Elster, R., Salamini, F., and Bartels, D.: The unusual sugar composition in leaves of the resurrection plant myrothamnus-flabellifolia, Physiologia Plantarum, 87, 223-226, 1993.

Clarke, A. and Kapustin, V.: Hemispheric aerosol vertical profiles: Anthropogenic impacts on optical depth and cloud nuclei, Science, 329, 1488-1492, 2010.

DeCarlo, P. F., Kimmel, J. R., Trimborn, A., Northway, M. J., Jayne, J. T., Aiken, A. C., Gonin, M., Fuhrer, K., Horvath, T., Docherty, K. S., Worsnop, D. R., and Jimenez, J. L.: Field-Deployable, High-Resolution, Time-of-flight Aerosol Mass Spectrometer, Anal. Chem., 78, 8281-8289, 2006.

Drewnick, F., Hings, S. S., DeCarlo, P., Jayne, J. T., Gonin, M., Fuhrer, K., Weimer, S., Jimenez, J. L., Demerjian, K. L., Borrmann, S., and Worsnop, D. R.: A New Time-of-Flight Aerosol Mass Spectrometer (ToF-AMS)-Instrument Description and First Field Deployment, Aerosol Sci. Tecnol., 39, 637-658, 2005.

Frossard, A. A., Shaw, P. M., Russell, L. M., Kroll, J. H., Canagratna, M. R., Worsnop, D. R., Quinn, P. K., and Bates, T. S.: Springtime Arctic haze contributions of submicron organic particles from European and Asian combustion sources, J. Geophys. Res., 116, D05205, doi:10.1029/2010JD015178, 2011.

Gilardoni, S., Russell, L. M., Sorooshian, A., Flagan, R. C., Seinfeld, J. H., Bates, T. S., Quinn, P. K., Allan, J. D., Williams, B., Goldstein, A. H., Onasch, T. B., and Worsnop, D. R.: Regional variations of organic functional groups in aerosol particles on four U.S. east coast platforms during the International Consortium for Atmospheric Research on Transport and Transformation 2004 campaign, J. Geophys. Res., 112, D10S27, doi:10.1029/2006JD007737, 2007.

Goldstein, A. H. and Galbally, I. E.: Known and unexplored organic constituents in the earth's atmosphere, Environ. Sci. Technol., 41, 1514-1521, 2007.

Guenther, A., Zimmerman, P. R., Harley, P. C., Russell, K. M., and Fall, R.: Isoprene and monoterpene emission rate variability: Model evaluations and sensitivity analyses, J. Geophys. Res., 98, 12609-12617, doi:10.1029/93JD00527, 1993.

Hallquist, M., Wenger, J. C., Baltensperger, U., Rudich, Y., Simpson, D., Claeys, M., Dommen, J., Donahue, N. M., George, C., Goldstein, A. H., Hamilton, J. F., Herrmann, H., Hoffmann, T., Iinuma, Y., Jang, M., Jenkin, M. E., Jimenez, J. L., Kiendler-Scharr, A., Maenhaut, W., McFiggans, G., Mentel, Th. F., Monod, A., Prévôt, A. S. H., Seinfeld, J. H., Surratt, J. D., Szmigielski, R., and Wildt, J.: The formation, properties and impact of secondary organic aerosol: current and emerging issues, Atmos. Chem. Phys., 9, 5155-5236, doi:10.5194/acp-9-51552009, 2009.

Hawkins, L. N. and Russell, L. M.: Oxidation of ketone groups in transported biomass burning aerosol from the 2008 Northern California Lightning Series fires, Atmos. Environ., 44, 41424154, 2010.
Hawkins, L. N., Russell, L. M., Covert, D. S., Quinn, P. K., and Bates, T. S.: Carboxylic acids, and sulfates, and organosulfates in processed continental organic aerosol over the southeast $\mathrm{Pa}$ cific Ocean during VOCALS-Rex 2008, J. Geophys. Res., 115, D13201, doi:10.1029/2009JD013276, 2010.

Hildemann, L. M., Rogge, W. F., Cass, G. R., Mazurek, M. A., and Simoneit, B. R. T.: Contribution of primary aerosol emissions from vegetation-derived sources to fine particle concentrations in Los Angeles, J. Geophys. Res., 101, 19541-19549, doi:10.1029/95JD02136, 1996.

Hitchcock, A.: aXis 2000, available at: http://unicorn.mcmaster.ca/ aXis2000.html, last access: March 2013.

Jimenez, J. L., Canagaratna, M. R., Donahue, N. M., Prevot, A. S. H., Zhang, Q., Kroll, J. H., DeCarlo, P. F., Allan, J. D., Coe, H., Ng, N. L., Aiken, A. C., Docherty, K. S., Ulbrich, I. M., Grieshop, A. P., Robinson, A. L., Duplissy, J., Smith, J. D., Wilson, K. R., Lanz, V. A., Hueglin, C., Sun. Y. L., Tian, J., Laaksonen, A., Raatikainen, T., Rautiainen, J., Vaattovaara, P., Ehn, M., Kulmala, M., Tomlinson, J. M., Collins, D. R., Cubison, M. J., Dunlea, E. J., Huffman, J. A., Onasch, T. B., Alfarra, M. R., Williams, P. I., Bower, K., Kondo, Y., Schneider, J., Drewnick, F., Borrmann, S., Weimer, S., Demerjian, K., Salcedo, D., Cottrell, L., Griffin, R., Takami, A., Miyoshi, T., Hatakeyama, S., Shimono, A., Sun, J. Y., Zhang, Y. M., Dzepina, K., Kimmel, J. R., Sueper, D., Jayne, J. T., Herndon, S. C., Trimiborn. A. M., Williams, L. R., Wood, E. C., Middlebrook, A. M., Kolb, C. E., Baltensperger, U., and Wornsop, D. R. : Evolution of Organic Aerosols in the Atmosphere, Science, 326, 1525-1529, 2009.

Kapustin, V. N., Clarke, A. D., Schinozuka, Y., Howell, S., Brekhovskikh, V., Nakajima, T., and Higurashi, A.: On the determination of a cloud condensation nuclei from satellite: Challenges and possibilities, J. Geophys. Res., 111, D04202, doi:10.1029/2004JD005527, 2006.

Kilcoyne, A. L. D., Tyliszczak, T., Steele, W. F., Fakra, S., Hitchcock, P., Franck, K., Anderson, E., Harteneck, B., Rightor, E. G., Mitchell, G. E., Hitchcock, A. P., Yang, L., Warwick, T., and Ade, H.: Interferometer controlled scanning transmission X-ray microscopes at the advanced light source, J. Synchroton Rad. 10, 125-136, 2003.

Kittelson, D. B.: Engines and nanoparticles: A review, J. Aerosol Sci., 29, 575-588, 1998.

Leaitch, W. R., Macdonald, A. M., Brickell, P. C., Liggio, J., Sjostedt, S. J., Vlasenko, A., Bottenheim, J. W., Huang, L., Li, S.M., Liu, P. S. K., Toom-Sauntry, D., Hayden, K. A., Sharma, S., Schantz, N. C., Wiebe, H. A., Zhang, W., Abbatt, J. P. D., Slowik, J. G., Chang, R. Y.-W., Russell, L. M., Schwartz, R. E., Takahama, S., Jayne, J. T., and Ng, N. L.: Temperature response of the submicron organic aerosol from temperate forests, Atmos. Environ., 45, 6696-6704, 2011.

Liu, S., Day, D. A., Shields, J. E., and Russell, L. M.: Ozone-driven daytime formation of secondary organic aerosol containing carboxylic acid groups and alkane groups, Atmos. Chem. Phys., 11, 8321-8341, doi:10.5194/acp-11-8321-2011, 2011.

Liu, S., Ahlm, L., Day, D. A., Russell, L. M., Zhao, Y., Gentner, D. R., Weber, R. J., Goldstein, A. H., Jaoui, M., Offenberg, J. H., Kleindienst, T. E., Rubitschun, C., Surratt, J. D., Sheesley, R. J., and Scheller, S.: Secondary organic aerosol formation from fossil fuel sources contribute majority of summertime organic mass at Bakersfield, J. Geophys. Res., 117, D00V26, 
doi:10.1029/2012JD018170, 2012.

Macdonald, A. M., Leaitch, W. R., Abbat, J. P. D., Ahlm L., AlBasheer, W., Betram, A. K., Buller, J., Campuzano-Jost, P., Chan, E., Corbin, J., Cziczo, D. J., Elford, A., Hayden, K. L., Herckes, P., Lee, A. K. Y., Li, S. -M., Liggio, J., Liu, P. S. K., Mihele, C., Noone, K. J., Pierce, J. R., Russell, L. M., Toom-Sauntry, D., Schroder, J., Sharma, S., Sheppard, A., Sjostedt, S. J., Slowik, J. G., Strawbridge, K., Stupple, G., Vlasenko, A., Wainwright, C. D., Wang, Y., Wentzell, J., Allan Wiebe, H., and Wong, J. P. S.: Overview of WACS 2010: Biogenic Aerosol Formation, Mountain Flows and CCN, Atmos. Chem. Phys. Discuss., in preparation, 2013.

Maria, S. F., Russell, L. M., Turpin, B. J., Porcja, R. J., Campos, T. L., Weber, R. J., and Huebert, B. J.: Source signatures of carbon monoxide and organic functional groups in Asian Pacific Regional Aerosol Characterization Experiment (ACEAsia) submicron aerosol types, J. Geophys. Res., 108, 8637, doi:10.1029/2003JD003703, 2003.

Mudelsee, M.: Climate Time Series Analysis, vol. 42 of Atmospheric and Oceanographic Sciences Library, Springer, Heidelberg, 2010.

Paatero, P. and Tapper, U.: Positive Matrix Factorization: A non-negative factor model with optimal utilization of error estimates of data values, Environmetrics, 5, 111-126, doi:10.1002/env.3170050203, 1994.

Pierce, J. R., Leaitch, W. R., Liggio, J., Westervelt, D. M., Wainwright, C. D., Abbatt, J. P. D., Ahlm, L., Al-Basheer, W., Cziczo, D. J., Hayden, K. L., Lee, A. K. Y., Li, S.-M., Russell, L. M., Sjostedt, S. J., Strawbridge, K. B., Travis, M., Vlasenko, A., Wentzell, J. J. B., Wiebe, H. A., Wong, J. P. S., and Macdonald, A. M.: Nucleation and condensational growth to $\mathrm{CCN}$ sizes during a sustained pristine biogenic SOA event in a forested mountain valley, Atmos. Chem. Phys., 12, 3147-3163, doi:10.5194/acp-12-3147-2012, 2012.

Roberts, G. C., Nenes, A., Seinfeld, J. H., and Andreae, M. O.: Impact of biomass burning on cloud properties in the Amazon Basin, J. Geophys. Res., 108, 4062, doi:10.1029/2001JD000985, 2003.

Rogge, W. F., Hildemann, L. M., Mazurek, M. A., Cass, G. R., and Simoneit, B. R. T.: Sources of fine organic aerosol. 4. Particulate abrasion products from leaf surfaces of urban plants, Environ. Sci. Technol., 27, 2700-2711, 1993.

Russell, L. M., Takahama, S., Liu, S., Hawkins, L. N., Covert, D. S., Quinn, P. K., and Bates, T. S.: Oxygenated fraction and mass of organic aerosol from direct emission and atmospheric processing measured on the R/V Ronald Brown during TEXAQS/GoMACCS 2006, J. Geophys. Res., 114, D00F05, doi:10.1029/2008JD011275, 2009.
Schwartz, R. E., Russell, L. M., Sjostedt, S. J., Vlasenko, A., Slowik, J. G., Abbatt, J. P. D., Macdonald, A. M., Li, S. M., Liggio, J., Toom-Sauntry, D., and Leaitch, W. R.: Biogenic oxidized organic functional groups in aerosol particles from a mountain forest site and their similarities to laboratory chamber products, Atmos. Chem. Phys., 10, 5075-5088, doi:10.5194/acp-10-50752010, 2010.

Shakya, K. M., Liu, S., Takahama, S., Russell, L. M., Keutsch, F. N., Galloway, M. M., Shilling, J.E., Hiranuma, N., Song, C., Kim, H., Paulson, S.E., Pfaffenberger, L., Barmet, P., Slowik, J., Prevot, A. S. H., Dommen, J., and Baltensperger, U.: Similarities in STXM-NEXAFS spectra of atmospheric particles and secondary organic aerosol generated from glyoxal, $\alpha$-pinene, isoprene, 1,2,4-trimethylbenzene, and d-limonene, Aerosol Sci. Technol., 47, 543-555, doi:10.1080/02786826.2013.772950, 2013.

Takahama, S., Gilardoni, S., Russell, L. M., and Kilcoyne, A. L. D.: Classification of multiple types of organic carbon composition in atmospheric particles by scanning transmission X-ray microscopy analysis, Atmos. Environ., 41, 9435-9451, 2007.

Takahama, S., Liu, S., and Russell, L. M.: Coatings and clusters of carboxylic acids in carbon-containing atmospheric particles from spectromicroscopy and their implications for cloudnucleating and optical properties, J. Geophys. Res., 115, D01202, doi:10.1029/2009JD012622, 2010.

Takahama, S., Schwartz, R. E., Russell, L. M., MacDonald, A. M., Sharma, S., and Leaitch, W. R.: Organic functional groups in aerosol particles from burning and non-burning forest emissions at a high-elevation mountain site, 11, 6367-6386, 2011.

Tsigaridis, K. and Kanakidou, M.: Secondary organic aerosol importance in the future atmosphere, Atmos. Environ., 41, 46824692, 2007.

Ulbrich, I. M., Canagaratna, M. R., Zhang, Q., Worsnop, D. R., and Jimenez, J. L.: Interpretation of organic components from Positive Matrix Factorization of aerosol mass spectrometric data, Atmos. Chem. Phys., 9, 2891-2918, doi:10.5194/acp-9-2891-2009, 2009.

Wong, J. P. S., Lee, A. K. Y., Slowik, J. G., Cziczo, D. J., Leaitch, W. R., Macdonald, A., and Abbatt, J. P. D.: Oxidation of ambient biogenic secondary organic aerosol by hydroxyl radicals: Effects on cloud condensation nuclei activity, Geophys. Res. Lett., 38, L22805, doi:10.1029/2011GL049351, 2011. 